\title{
Methanol degradation mechanisms and permeability phenomena in novolac epoxy and
} polyurethane coatings

Wang, Ting; Luo, Shicong; Wang, Chenyu; Wang, Jing; Weinell, Claus Erik; Dam-Johansen, Kim; Segura, Juan José; Graversen, Erik; Kiil, Søren

Published in:

Journal of Coatings Technology and Research

Link to article, DOI:

$10.1007 / \mathrm{s} 11998-020-00446-\mathrm{w}$

Publication date:

2021

Document Version

Peer reviewed version

Link back to DTU Orbit

Citation $(A P A)$ :

Wang, T., Luo, S., Wang, C., Wang, J., Weinell, C. E., Dam-Johansen, K., Segura, J. J., Graversen, E., \& Kiil, S. (2021). Methanol degradation mechanisms and permeability phenomena in novolac epoxy and polyurethane coatings. Journal of Coatings Technology and Research, 18, 831-842. https://doi.org/10.1007/s11998-02000446-w

\section{General rights}

Copyright and moral rights for the publications made accessible in the public portal are retained by the authors and/or other copyright owners and it is a condition of accessing publications that users recognise and abide by the legal requirements associated with these rights.

- Users may download and print one copy of any publication from the public portal for the purpose of private study or research.

- You may not further distribute the material or use it for any profit-making activity or commercial gain

- You may freely distribute the URL identifying the publication in the public portal 


\title{
Methanol degradation mechanisms and permeability phenomena in novolac epoxy and polyurethane coatings
}

\author{
Ting Wang ${ }^{\mathrm{a}}$, Shicong Luo ${ }^{\mathrm{a}}$, Chenyu Wang ${ }^{\mathrm{a}}$, Jing Wang ${ }^{\mathrm{a}}$, Claus Erik Weinell ${ }^{\mathrm{a}}$, Kim Dam- \\ Johansen $^{\mathrm{a}}$, Juan José Segura ${ }^{\mathrm{b}}$, Erik Graversen ${ }^{\mathrm{b}}$, Søren Kiil ${ }^{\mathrm{a}}$ \\ ${ }^{a}$ CoaST, Department of Chemical and Biochemical Engineering, Technical University of \\ Denmark (DTU), Building 229, DK-2800 Kgs. Lyngby, Denmark. \\ ${ }^{\mathrm{b}}$ Hempel A/S, Lundtoftegårdsvej 91, DK-2800 Kgs. Lyngby, Denmark
}

\begin{abstract}
On a global scale, methanol is one of the most important feedstocks and used widely as solvent and co-solvent. However, due to the polar nature and associated ability to conduct current, the small molecule can take part in galvanic corrosion of metal storage tanks and degrade the barrier properties of protective coatings.

In the present work, we investigated the degradation of two novolac epoxy coatings and a polyurethane (PU) coating exposed to methanol with the aim of quantifying the various degradation paths. Absorption and desorption rates were measured and the thermomechanical properties followed by dynamic mechanical analysis. For evaluation of the coating barrier properties (i.e., breakthrough time and steady state permeation rates of methanol), permeation cells were applied.

During methanol absorption, simultaneous leaching of certain coating ingredients and bonding of methanol to the binder matrix via hydrogen bonds were evidenced. In terms of classification, the bonding of methanol took place by two types of mechanisms. In Type I, the methanol molecule forms a single hydrogen bond to the coating network, thereby acting as a plasticizer, which decreases the coating storage modulus and glass transition temperature. For Type II bonding of methanol, on the other hand, two hydrogen bonds to the coating network form per molecule, resulting in so-called physical crosslinking. The Type I mechanism boosted segmental mobility and contributed to the leaching of the plasticizer benzyl alcohol from the novolac epoxy coatings and residual solvents (i.e., naphtha and xylene) from the PU coating. Following the methanol desorption, and attributed to an increased effective crosslinking density from Type II bound
\end{abstract}


methanol, the novolac epoxy and PU coatings exhibited significant increases in the glass transition temperatures. In addition, for the three coatings, a gradual decline in the permeability rate of methanol was observed over time. These enhanced (and unexpected) barrier properties result from a combination of effects ascribed to Type II bound methanol and the leaching process.

\section{Keywords}

Novolac epoxy, Polyurethane, Methanol absorption and desorption, Permeability, Hydrogen bonding

\section{Introduction}

High-performance organic coatings are used extensively to protect metallic structures in corrosive environments. The coatings delay the penetration and effects of aggressive and/or corrosive species such as organic chemicals and aqueous solutions of salts, acids or alkalis, thereby prolonging the lifetime of the underlying substrates. Common examples are two-component epoxy-amine and polyurethane (PU) coatings. The former types have excellent adhesion to metals and good resistance to chemicals, whereas the latter is known for its superior resistance to weathering. ${ }^{1}$ For chemical and solvent resistance in harsh (heavy duty) applications, phenolic novolac epoxy coatings, with their higher crosslinking densities compared to bisphenol A or bisphenol $\mathrm{F}$ epoxy resins, are the preferred choice. ${ }^{1,2}$ However, despite the protective abilities, the coatings themselves will also undergo physical and/or chemical degradation in contact with the chemicals, and the lifetime of a coating system is often limited by the permeation rate or breakthrough time of these chemicals.

The penetration of solvent(s) usually causes some kind of physical degradation of the coating systems. Water, in particular, has been extensively studied ${ }^{3-10}$ and found to cause swelling, cracking, and reduction of mechanical properties and glass transition temperature of epoxy and polyester coatings. Organic molecules, such as kerosene, ${ }^{11} 1,1,1$ trichloroethane, and toluene, ${ }^{12}$ were reported to act as plasticizers and reduce the mechanical properties of certain coating systems like butyl rubber composites and polyesters. In comparison to water, other polar organic solvents (e.g., methanol, ethanol, and acetone) have a higher affinity to the coating systems, thereby resulting in more severe physical degradation (i.e., a higher degree of swelling and a greater loss of flexural strength). ${ }^{2,13,14}$ 
Along with the physical degradation caused by water, aqueous solutions of acids, alkalis, or salts can further induce chemical degradation of the coating films. ${ }^{13}$ Examples include hydrolysis, transesterification, and oxidation. Abeysinghe et al. ${ }^{10}$ investigated the physicochemical changes occurring in crosslinked polyesters during immersion in electrolyte solutions of $\mathrm{NaCl}, \mathrm{H}_{2} \mathrm{SO}_{4}$ and $\mathrm{NaOH}$. The degradation of polyester resins follows a sequence of water uptake, swelling, and leaching of non-immobilized substances and hydrolysis products (i.e., isophthalic acid and propylene glycol). In addition, functional groups, such as urethanes of PU coatings and the ether linkages of epoxy coatings (to a less extent), are susceptible to acid-induced hydrolysis. ${ }^{2}$

Most studies have focused on the degradation of organic coatings exposed to water or electrolyte solutions, whereas research on the effects of organic molecules is comparatively limited, keeping in mind that organic coatings are often the preferred choice for example as tank linings for the storage of alcohols, as well as aromatic and aliphatic solvents. Methanol, in particular, is one of the most important chemical raw materials with widespread application as a feedstock, a solvent and co-solvent. ${ }^{15}$ Its high rate of diffusivity and ability to induce swelling, softening, and weakening of coating adhesion, make it very aggressive to organic coatings. ${ }^{14}$ Moreover, as a conductive polar molecule, methanol can impose galvanic corrosion of metal substrates, thereby leading to potential failures of carbon steel tanks. ${ }^{16}$ To avoid this, as an electrically non-conductive barrier between the liquid methanol (including any dissolved impurities) and the tank material, epoxy coatings are commonly applied as tank linings with two to three layers in a total minimum dry film thickness (DFT) of $300 \mu \mathrm{m}$. To further improve their resistance to methanol, curing at an elevated temperature is necessary to form highly crosslinked epoxy coatings.

\section{Experimental methods for coating degradation studies and aims of the work}

Various technologies have been utilized to study the degradation of organic coatings exposed to chemicals. The most common method is immersion, ${ }^{3-18}$ where coating films are placed in a chemical solution and analyzed periodically for physical and/or chemical changes. Analytical methods include optical or electron microscopes to detect visual degradation like cracks, ${ }^{10,18}$ IR spectra to analyze the chemical degradation ${ }^{13,19,22}$ or quantify diffusion of chemicals, ${ }^{20}$ and dynamic mechanical analysis (DMA) to monitor the degradation of mechanical

properties. $^{3,5,6,9,21,22}$ In addition, permeation cells are applicable to measure the rate of diffusion or permeation of chemicals across organic coatings. More specifically, two types of cells are widely 
used: two-chamber permeation cell for electrolyte solutions $\mathrm{s}^{23,24}$ and one-chamber permeation cells for highly volatile compounds. ${ }^{25,26}$ Using a free coating film, the two-chamber cell separates an electrolyte solution from a chamber containing only demineralized water, and the amount of permeated electrolyte is obtained by measuring the concentration development in the water. Conversely, the one-chamber permeation cell measures the weight loss of the entire cell to determine the amount of the penetrant permeating (and subsequently evaporating) across a free coating film from the chamber. Using mathematical models of the process in the set-up, diffusion coefficients can be estimated by fitting of simulations to transient experimental data. ${ }^{27}$

In the present work, using a one-chamber permeation cell, we aim to study the transient development of the barrier properties of selected novolac epoxy and PU coatings during methanol exposure and compare the results to experimental data of pertinent reference materials. In addition, for a simultaneous quantification of the mechanical properties of the coating films, DMA analysis is applied. Finally, mechanisms are proposed for the degradation behaviours of the two coating types.

\section{Experimental}

\section{Materials}

The coatings used in the experimental series were commercial formulations from Hempel A/S, Denmark, with details provided in Table 1. Air-less spraying on non-stick polypropylene substrates of size $300 \mathrm{~mm} \times 200 \mathrm{~mm}$ from Lyreco A/S, Denmark, allowed us to obtain rectangular free coating films of size $30 \mathrm{~mm} \times 10 \mathrm{~mm}$ for the immersion experiments and subsequent DMA analysis, and circular ones of $50 \mathrm{~mm}$ diameter for the permeation cells. The curing process was 14 days at room temperature, followed by post-curing at $60{ }^{\circ} \mathrm{C}$ for two days. Using an Elcometer 355 coating thickness gauge, the coating DFT was measured to $300-400 \mu \mathrm{m}$ for novolac epoxy coatings and $150-200 \mu \mathrm{m}$ for PU coatings. 
Table 1: Main components of the experimental coatings. Additional details can be found in an earlier work on acid degradation of organic coatings. ${ }^{23}$ NE-CA=Novolac Epoxy-Cycloaliphatic Amine. NE-PA= Novolac Epoxy-Polyamide.

\begin{tabular}{lllll}
\hline Coating & Resin & Curing agent & $\mathrm{R}^{\mathrm{a}}$ & Fillers/pigments \\
\hline $\begin{array}{l}\text { Novolac epoxy, } \\
100 \% \text { solids (NE-CA) }\end{array}$ & $\begin{array}{l}\text { Novolac } \\
\text { epoxy resin }\end{array}$ & $\begin{array}{l}\text { Cycloaliphatic } \\
\text { amine (CA) }\end{array}$ & 0.9 & $\begin{array}{l}\text { Talc, feldspar, and } \\
\text { titanium dioxide }\end{array}$ \\
\hline $\begin{array}{l}\text { Novolac epoxy, } \\
100 \% \text { solids (NE-PA) }\end{array}$ & $\begin{array}{l}\text { Novolac } \\
\text { epoxy resin }\end{array}$ & Polyamide (PA) & 1.0 & $\begin{array}{l}\text { Quartz, baryte, and } \\
\text { titanium dioxide }\end{array}$ \\
\hline $\begin{array}{l}\text { Polyurethane (PU), } \\
\text { solvent-based }\end{array}$ & $\begin{array}{l}\text { Polymeric } \\
\text { polyol }\end{array}$ & Isocyanate & 1.1 & $\begin{array}{l}\text { Baryte, calcium carbonate, } \\
\text { and titanium dioxide }\end{array}$ \\
\hline
\end{tabular}

a: $\mathrm{R}=\mathrm{M}_{\mathrm{Eq}}\left(\right.$ Curing agent) $/ \mathrm{M}_{\mathrm{Eq}}($ Resin $)$ is the ratio of curing agent to binder equivalents, defining the relative mixture stoichiometry of functional groups.

For reference comparison in the permeation experiments, the methanol permeability rate in two thermoplastic films (i.e., low density polyethylene, LDPE, and poly(methyl methacrylate), PMMA, were measured and compared to the thermoset coatings. The LDPE films, with a thickness of 0.2 $\mathrm{mm}$ and a density of $920 \mathrm{~kg} / \mathrm{m}^{3}$, were obtained from Goodfellows, UK. The PMMA films, $1 \mathrm{~mm}$ in thickness and a density of $1190 \mathrm{~kg} / \mathrm{m}^{3}$, were obtained from RIAS A/S, Denmark.

Methanol (99.8\%) and ethanol (99.8\%) were supplied by Sigma-Aldrich Denmark A/S. To seal the permeation cell, ethylene-propylene-diene rubber (EPDM) O-rings from M Seals A/S, Denmark, were used. These O-rings have excellent resistance to polar solvents (i.e., alcohols and ketones) and a working temperature from -50 to $200{ }^{\circ} \mathrm{C}$. Two sizes were used: 1) $42 \mathrm{~mm}$ inner diameter and $3 \mathrm{~mm}$ thickness, 2) $3 \mathrm{~mm}$ inner diameter and $2 \mathrm{~mm}$ thickness.

\section{Absorption and desorption experiments}

Methanol absorption and desorption experiments were performed on free films of NE-CA, NE-PA and PU. Rectangular samples were immersed in methanol at room temperature. At regular intervals, the films were withdrawn, dried with a paper towel to remove surface liquid, and weighted before being left to dry, also at room temperature. After seven days, weight measurements and DMA (specified below) were conducted on these methanol-exposed samples. The compositions of the remaining methanol solutions were analyzed using gas chromatography-mass spectrometry (GCMS), as specified below. 
For comparison, the effects on the coating properties of demineralized water and ethanol exposure were also investigated, along with absorption and desorption experiments.

\section{Permeation rate experiments}

To monitor the permeation rate of methanol through the NE-CA, NE-PA, and PU coating films, as well as LDPE and PMMA films, a custom-made, one-chamber permeation cell was designed and constructed (Fig. 1).

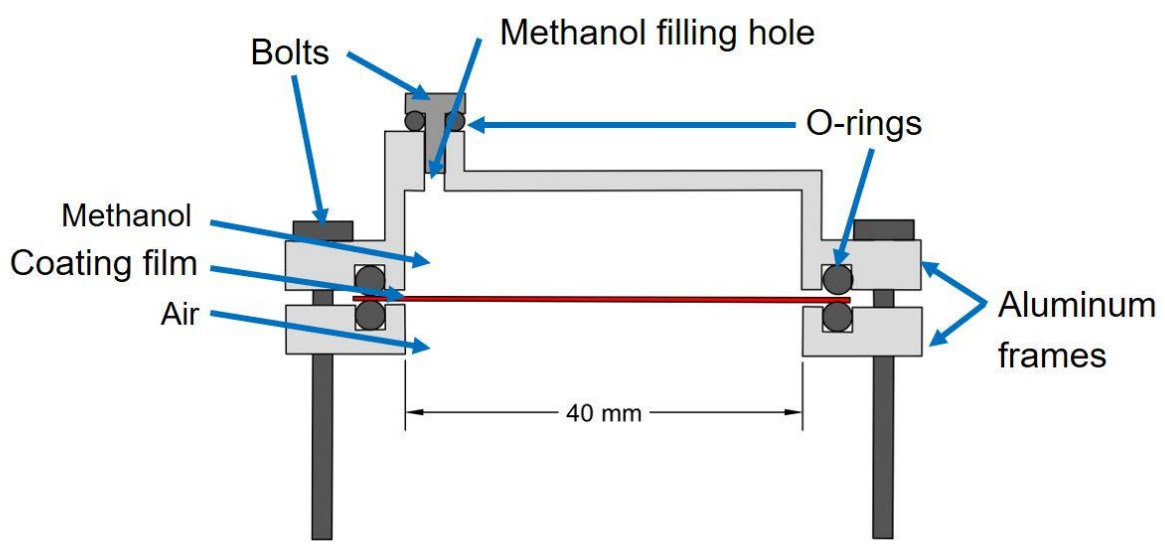

Fig. 1: Schematic cross-section view of the one-chamber permeation cell used in the experiments. The chamber volume is $12.5 \mathrm{~mL}$.

To initiate an experiment, a circular free film was placed between the two aluminium parts of the cell, sealed with two O-rings of $42 \mathrm{~mm}$ inner diameter and fastened using stainless steel bolts. After assembly of the cell, methanol was added from an opening in the top of the cell, specifically designed to prevent spills during the filling process. To seal the opening after methanol loading, a bolt in combination with the O-ring of $3 \mathrm{~mm}$ inner diameter was used.

During an experiment, methanol molecules diffuse through the film and evaporate on the opposite side with an associated weight decrease of the entire cell. In general, the evaporation rate of methanol is several orders of magnitude higher than the permeation rate through a polymer film, ${ }^{25}$ and any gas phase mass transport limitations can, therefore, be neglected. Consequently, the weight reduction rate of the cell can be considered equal to the permeation rate of methanol. The weight loss of the cell was measured using an analytical balance from Sartorius (ENTRIS623I-1S) with an accuracy of $0.001 \mathrm{~g}$, and the permeation experiments were all carried out at room temperature. 
In order to determine the undesired methanol loss through the O-rings, a stainless steel plate of 50 $\mathrm{mm}$ diameter and a thickness of approximately $500 \mu \mathrm{m}$ was used in place of a film sample in a permeation cell experiment. The observed average weight loss was found to be smaller than 1.0 mg after 192 hours, which amounts to less than $1.0 \%$ of the weight loss through a film sample after 168 hours. The methanol losses through the O-rings could, therefore, be neglected.

\section{Dynamic mechanical analysis}

Using a rheometer DHR-2 (TA Instruments) with a Film/Fiber Tension geometry, DMA tests were performed on the free rectangular films. Scans were run at a heating rate of $5^{\circ} \mathrm{C} / \mathrm{min}$ under $25 \mu \mathrm{m}$ axial displacement at a frequency of $1 \mathrm{~Hz}$.

\section{Gas chromatography-mass spectrometry}

After methanol absorption, the compositions of methanol solutions were analyzed by GC-MS using a Hewlett Packard (HP) 7890 gas chromatograph equipped with an HP 5977B Mass Selective Detector (Agilent, Santa Clara, CA, USA). The oven temperature was programmed to run from 60 to $230{ }^{\circ} \mathrm{C}$ at $10{ }^{\circ} \mathrm{C} / \mathrm{min}$. The compounds were separated using a $15 \mathrm{~m} \times 0.25 \mathrm{~mm}$ in diameter HP-5 ms Ultra Inert column coated with (5\%-phenyl)-methylpolysiloxane (Agilent) at a thickness of $0.25 \mu \mathrm{m}$. In a split mode (1:20), using an HP 4567A autosampler (Agilent) samples $(0.3 \mu \mathrm{l})$ were injected with helium as carrier gas at $1.2 \mathrm{ml} / \mathrm{min}$. The mass spectrometer was operated in an ionization energy of $70 \mathrm{eV}$ and a $\mathrm{m} / \mathrm{z}$ range of 40-550. For identification of compounds, the Spectral National Institute of Standards (NIST) search engine (Agilent) was used.

\section{Results and discussion}

This section presents results of the absorption-desorption experiments and permeation rate measurements, with an investigation into the degradation behaviours of novolac epoxy and PU coatings exposed to methanol.

\subsection{Methanol absorption and desorption}

The NE-CA, NE-PA, and PU films were immersed in methanol for different values of time, followed by unrestricted evaporation for 168 hours, and finally exposed to DMA measurements for the recording of the thermomechanical properties. In Fig. 2, the weight change of the NE-CA films, after the methanol absorption and subsequent desorption have taken place, is shown. 


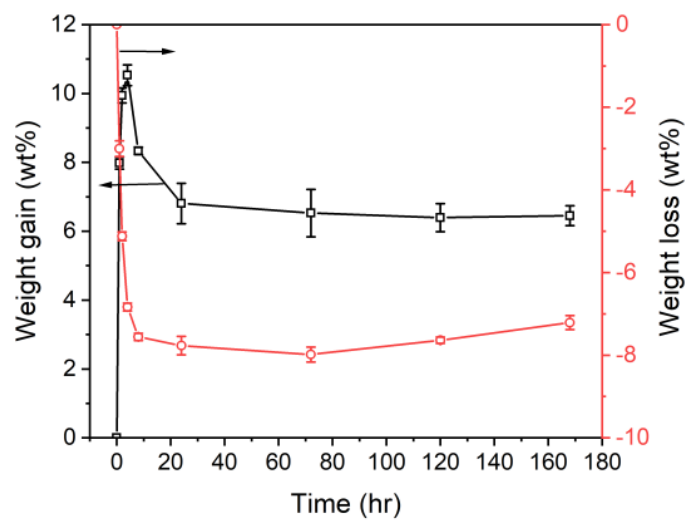

Fig. 2: The weight gain and subsequent long term weight loss (unrestricted evaporation for 168 hours at room temperature) of NE-CA films exposed to methanol immersion for different values of time. Note that each data point represents an individual coating sample. Standard deviations are shown with error bars.

Considering Fig. 2 as a transient experiment, the weight of the NE-CA films initially increases rapidly, and then begins to decline after about four hours. The initial weight gain is due to the absorption of methanol, while the latter weight loss results from leaching of non-immobilized substances, such as residual solvents, plasticizers, fillers and pigments. After removal of the absorbed methanol, the weight reduction caused by the leaching process varies as seen in Fig. 2. A rapid leaching (weight loss) takes place within the first four hours, but after 72 hours, the weight again increases slightly. The latter is most likely entirely caused by the incomplete removal (trapping) of methanol after desorption at room temperature. Table 2 presents the weight change of the NE-CA, NE-PA, and PU films after methanol absorption and desorption. 
Table 2: Coating properties and weight changes after immersion for 168 hours $\left(\mathrm{M}_{\mathrm{i}}\right)$ and unrestricted evaporation for 168 hours $\left(\mathrm{M}_{1}\right)$ of the NE-CA, NE-PA, and PU films.

\begin{tabular}{cccccc}
\hline Coating & Density $\left(\mathrm{kg} / \mathrm{m}^{3}\right)$ & $\mathrm{XLD}(\mathrm{mmol} / \mathrm{l})^{\mathrm{a}}$ & $\mathrm{M}_{\mathrm{i}}(\mathrm{wt} \%)$ & $\mathrm{M}_{\mathrm{l}}(\mathrm{wt} \%)$ & $\mathrm{M}_{\mathrm{m}}(\mathrm{wt} \%)^{\mathrm{b}}$ \\
\hline NE-CA & 1.29 & 6.38 & 6.45 & -7.21 & 13.66 \\
NE-PA & 1.39 & 7.79 & 10.59 & -2.12 & 12.71 \\
PU & 1.76 & 2.13 & 6.67 & -5.23 & 11.90 \\
\hline
\end{tabular}

a. Millimole crosslinks per litre dry coating film. Theoretical value, assuming full conversion of the limiting reactant.

b. $\mathrm{M}_{\mathrm{m}}=\mathrm{M}_{\mathrm{i}}-\mathrm{M}_{\mathrm{l}}$, is the approximate film weight gain of methanol after immersion for 168 hours.

After immersion for 168 hours, the weight uptake percentages of methanol for NE-CA, NE-PA, and PU films are all greater than $10 \mathrm{wt} \%$, indicating a high degree of swelling, which can be attributed to a high affinity of methanol to the novolac epoxy and PU coating networks. After unrestricted evaporation for 168 hours, all three films decline in weight, suggesting a significant leaching of coating ingredients. The absorption of methanol swells and plasticizes the coating network and increases segmental chain mobility, thereby contributing to the migration of nonimmobilized substances from the coating to the methanol solvent. Compared to NE-PA films, NECA films have a lower crosslinking density (XLD), which explains their relatively greater methanol uptake.

For identification of the leached substances, GC-MS was used to analyze the methanol solutions after the immersion experiments, and benzyl alcohol was found to be the main substance leaching from NE-CA and NE-PA films. Benzyl alcohol is a plasticizer and present in abundance in the curing agents of the two novolac epoxy coatings. On the other hand, substances leaching from the PU films were identified as residual solvents, i.e., naphtha and xylene isomers.

In Fig. 3, changes in the storage modulus and the loss factor [tan $(\delta)]$ of NE-CA films after methanol desorption as a function of immersion time are shown. 
(a)

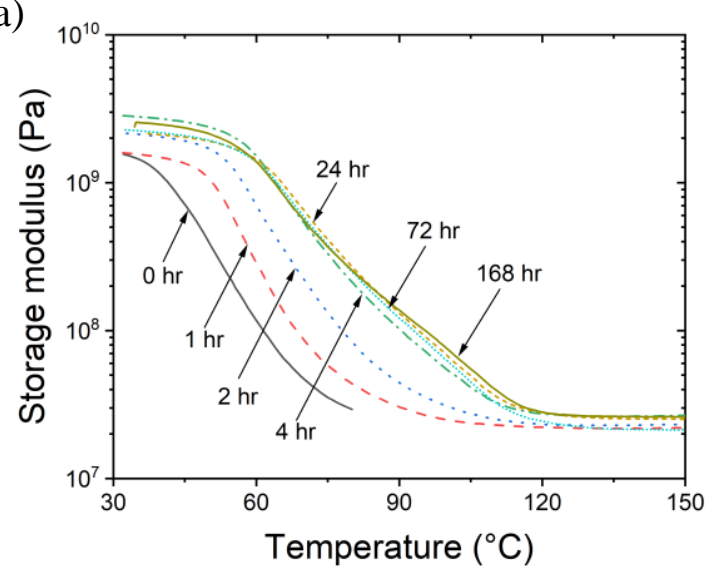

(b)

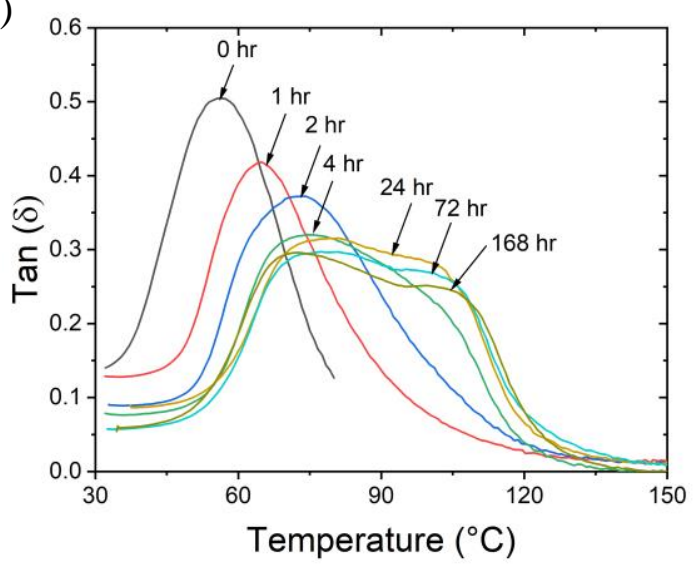

Fig. 3: DMA temperature scans of methanol-exposed NE-CA films after different immersion times and subsequent unrestricted evaporation at room temperature. (a) Storage modulus and (b) loss factor $[\tan (\delta)]$.

For the first four hours, due to leaching of benzyl alcohol, the storage modulus of the films (at this stage in the glassy state) gradually increases. The presence of benzyl alcohol (i.e., a molecule with a hydroxyl group), disrupts the interchain hydrogen bonds in the coating network and reduces the storage modulus of the otherwise more glassy and rigid film. After 24 hours immersion in methanol, the film storage modulus does not change significantly.

With longer immersion time, the peak of the loss factor shifts to higher temperatures as seen in Fig. 3(b), suggesting an increase in the glass transition temperature (normally estimated from the location of the peak position) of NE-CA films. Note also the broadening of the peak of the loss factor with time, transforming into an overlapping peak after 24 hours. The left hand peak starts to shift to lower temperatures after 24 hours. This shift is caused by residual methanol, providing a plasticizing effect. In order to verify the influence of benzyl alcohol and methanol, the glass transition temperature was plotted against the weight loss of NE-CA films as shown in Fig. 4. 


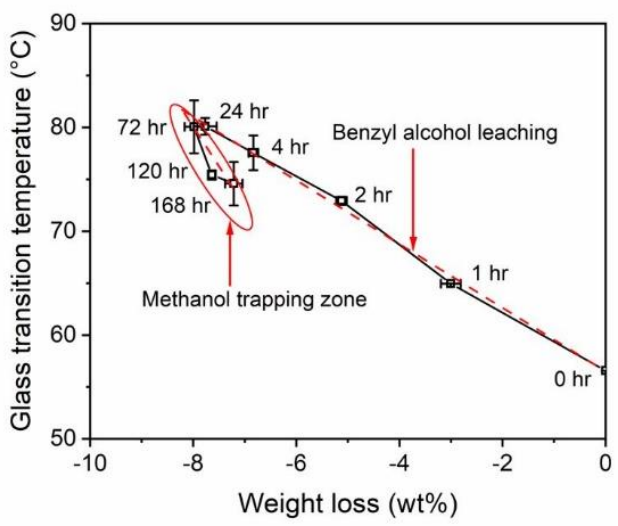

Fig. 4: The transient change of the average glass transition temperature against the weight loss of NE-CA films after the methanol desorption. The glass transition temperature was obtained from the peak position (left hand peak after 24 hours) in Fig. 3(b). At each data point, the immersion time is provided and the standard deviations are shown with error bars.

It can be seen that a nearly proportional increase of the glass transition temperature is observed with the weight reduction of NE-CA films, followed by a nearly linear decline with the weight increase caused by residual methanol. The correlations, indicating proportionality, suggest that the initial increase and latter decrease in the glass transition temperature are caused by the leaching of benzyl alcohol and the trapping of methanol, respectively. ${ }^{28}$

The emergence of the right hand peak of the loss factor suggests some enhanced mechanical properties at higher temperatures and an increase in the coating glass transition temperature. This phenomenon cannot be explained by the plasticizing effect of benzyl alcohol or methanol. Similar increases in the glass transition temperatures of epoxy coatings, due to water ingress, were observed and attributed to multiple hydrogen bonds of water to the coating network. ${ }^{6-8}$ Zhou and Lucas $^{7,8}$ proposed two types of bound water existing in epoxy resins. Type I bound water forms a single hydrogen bond with the epoxy network and gives a plasticizing effect; Type II bound water forms multiple hydrogen bonds, resulting in physical (secondary) crosslinking and contributes to an increase in the glass transition temperature in water saturated epoxy resin.

Analogue to water, methanol, apparently, is also able to form multiple hydrogen bonds to the novolac epoxy network, giving strong interactions. According to the number of hydrogen bonds, the bound methanol is divided into two types. Type I bound methanol forms a single hydrogen 
bond with the coating network, whereas Type II methanol forms two hydrogen bonds. Fig. 5(a) illustrates the two types of hydrogen bonding model of methanol in a novolac epoxy network.

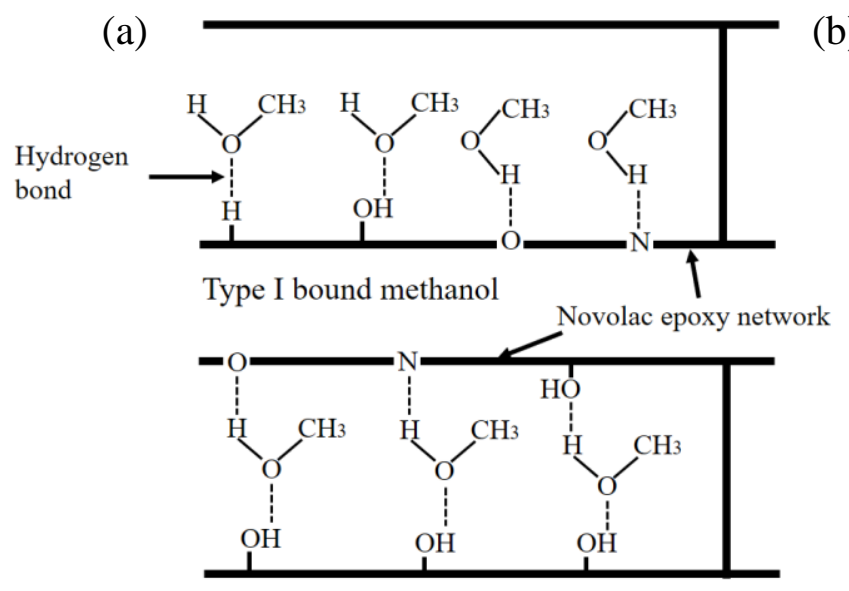

Type II bound methanol (b)

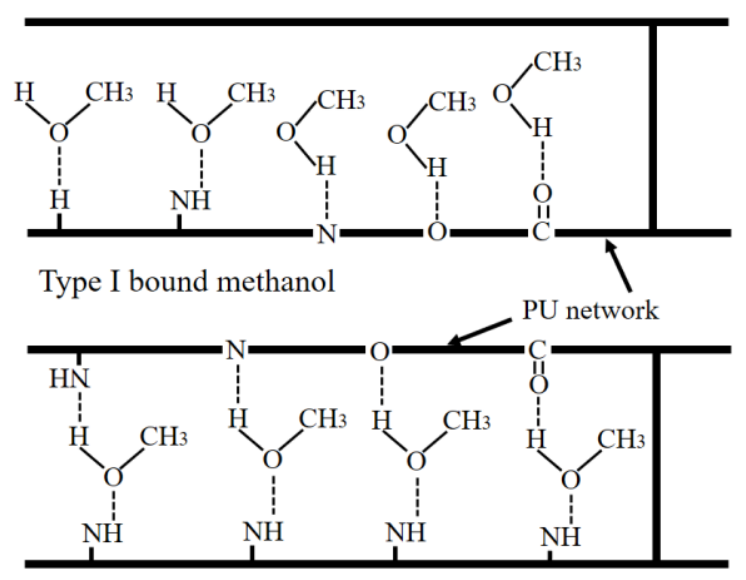

Type II bound methanol

Fig. 5: Potential methanol complexes in (a) novolac epoxy and (b) PU networks. For Type II bound methanol, due to the weak hydrogen bond energy, the $\mathrm{C}-\mathrm{H} \cdots \mathrm{O}$ hydrogen bonds are less important and not shown.

Type I bound methanol possesses a low activation energy and the molecules can diffuse and evaporate spontaneously at room temperature, while an elevated temperature, due to a high activation energy, is required to remove Type II bound methanol. Following desorption, both Type I and II bound methanol remains in the coating network. Type I bound methanol plasticizes the network, accounting for the decline in the glass transition temperature (the left hand peak of loss factor). In contrast, Type II bound methanol forms bridging between chain segments and restricts chain motions, resulting in physical crosslinking. The latter increases the effective crosslinking density, thereby increasing the molecular weights of polymer chains participating in the glass relaxation and displacing the observed broadening of the loss factor peak to higher temperatures ${ }^{5,6}$. A similar phenomenon was observed for NE-PA films in Fig. 6(a) for the peak of the loss factor, which shifts to lower temperatures due to residual Type I bound methanol and a peak at around $110^{\circ} \mathrm{C}$ that emerges as a result of Type II bound methanol. With longer immersion time, the right hand peak becomes more pronounced for the two novolac epoxy coatings, indicating the continuous formation of Type II bound methanol. 
(a)

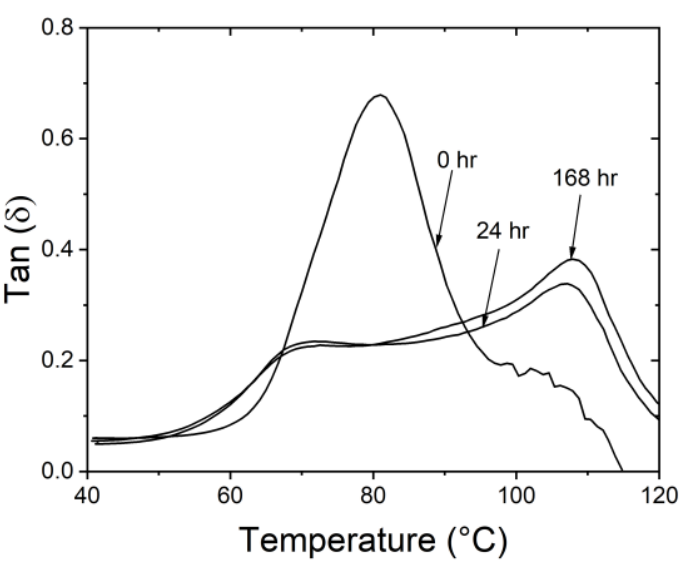

(b)

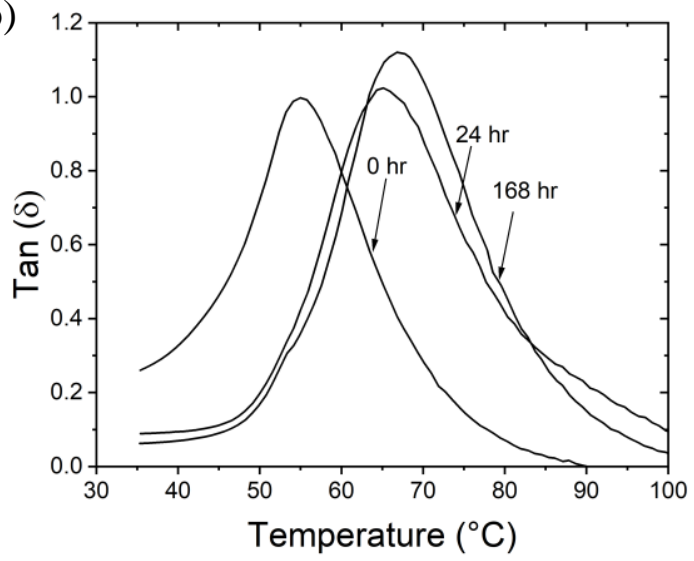

Fig. 6: Loss factors $[\tan (\delta)]$ of methanol-exposed (a) NE-PA and (b) PU films with different immersion times and subsequent unrestricted evaporation at room temperature.

For PU films, on the other hand, a single peak only can be observed as shown in Fig. 6(b). This is due to the complete removal of the residual solvents and Type I bound methanol during the desorption step. Compared to the NE-CA and NE-PA films, the PU film has a much lower crosslinking density (XLD in Table 2) and glass transition temperature that facilitates the methanol desorption process.

In an attempt to eliminate the influence of Type I bound methanol, NE-CA, NE-PA and PU films (with 168 hours immersion time) were additionally exposed to $60{ }^{\circ} \mathrm{C}$ for 168 hours. For these samples, DMA results are shown in Fig. 7.

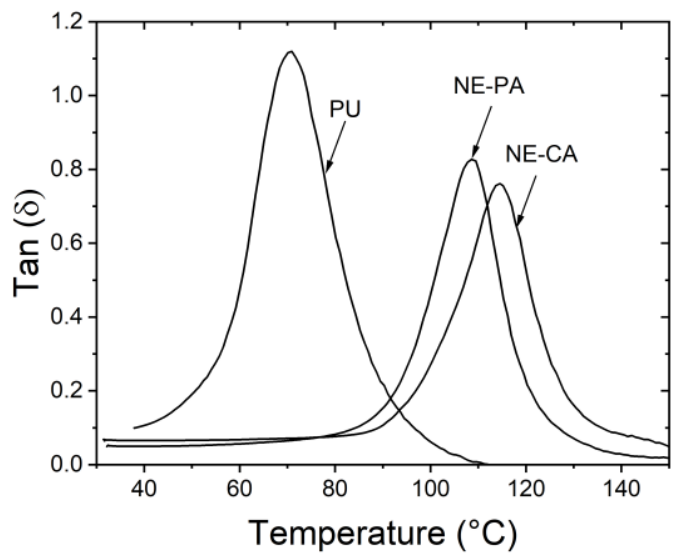

Fig. 7: Loss factors [ $\tan (\delta)]$ of NE-CA, NE-PA, and PU films with 168 hours methanol immersion. Prior to the DMA measurements, all films were allowed unrestricted evaporation for 168 hours at room temperature and another 168 hours at $60{ }^{\circ} \mathrm{C}$. 
A single peak of the loss factor is evident for the NE-PA and NE-CA films, suggesting a complete removal of the Type I bound methanol. In Table 3, the weight losses and glass transition temperatures following the heat treatment are shown.

Table 3: Weight loss (relative to the original non-exposed film), $\mathrm{M}_{1}$, and the glass transition temperature of the NE-CA, NE-PA, and PU coatings (168 hours methanol immersion).

\begin{tabular}{lccc}
\hline \multirow{2}{*}{ Coating } & \multirow{2}{*}{$\mathrm{M}_{1}(\mathrm{wt} \%)$} & \multicolumn{2}{c}{ Glass transition temperature $\left({ }^{\circ} \mathrm{C}\right)$} \\
\cline { 3 - 4 } & & Original & Methanol-immersed \\
\hline NE-CA & -9.33 & 56.2 & 113.6 \\
NE-PA & -5.41 & 82.6 & 108.6 \\
PU & -5.26 & 55.4 & 70.9 \\
\hline
\end{tabular}

Compared to the weight loss in Table 2, an additional 2-3 wt \% methanol was removed from the NE-CA and NE-PA coatings, while the weight of the PU coatings remains stable. After the methanol desorption, a significant increase in the glass transition temperature can be seen for all three films as a likely consequence of increased crosslinking density by Type II bound methanol. The NE-CA and NE-PA films have similar glass transition temperatures (about $110{ }^{\circ} \mathrm{C}$ ) after methanol exposure. This is due to similar physical crosslinking formed by Type II bound methanol. The two novolac epoxy coatings have the same novolac epoxy binder and were both cured with amine curing agents so that the similar type of hydrogen bonds should be formed. Moreover, the glass transition temperature after methanol exposure is close to the value of an epoxy-amine coating after water desorption. ${ }^{6}$ The energy of Type II bound methanol is expected to be close to Type II bound water due to the formation of similar types of hydrogen bonds (i.e., $\mathrm{O}-\mathrm{H} \cdots \mathrm{O}$ and $\mathrm{O}-\mathrm{H} \cdots \mathrm{N})$. However, after methanol exposure, the glass transition temperature of the PU film is significantly lower than the two novolac epoxy coatings. Methanol can form physical crosslinking with two hydrogen bonds to the PU network as shown in Fig. 5(b), but the $\mathrm{N}-\mathrm{H} \cdots \mathrm{O}$ hydrogen bond (present in the cured PU network) only has approximately half the bonding strength of the $\mathrm{O}-\mathrm{H} \cdots \mathrm{O}$ and $\mathrm{O}-\mathrm{H} \cdots \mathrm{N}$ hydrogen bonds, i.e., $8-12$ against $20-25 \mathrm{~kJ} / \mathrm{mol}^{29}{ }^{29}$ Therefore, a lower energy is required to break the hydrogen bonding formed by the Type II bound methanol in the PU network. This explains the low glass transition temperature of the PU film after methanol exposure. 


\subsection{Methanol permeation rate}

Using the one-chamber permeation cell, the permeability and permeation rate of methanol through NE-CA, NE-PA, and PU films were measured, and the results are presented in Fig. 8.

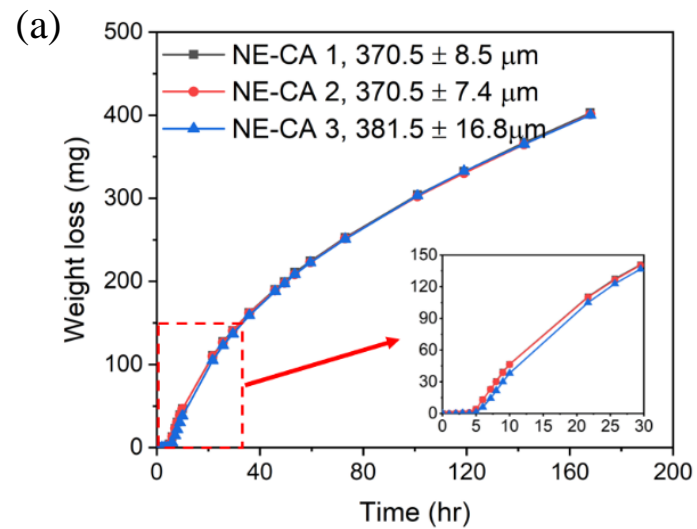

(b)

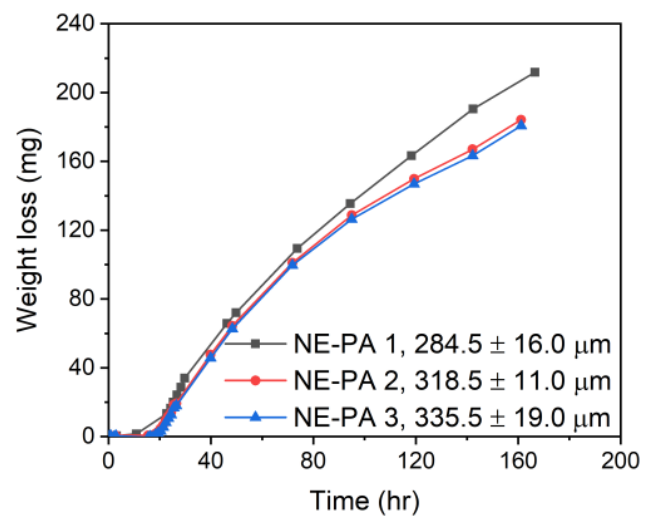

(c)

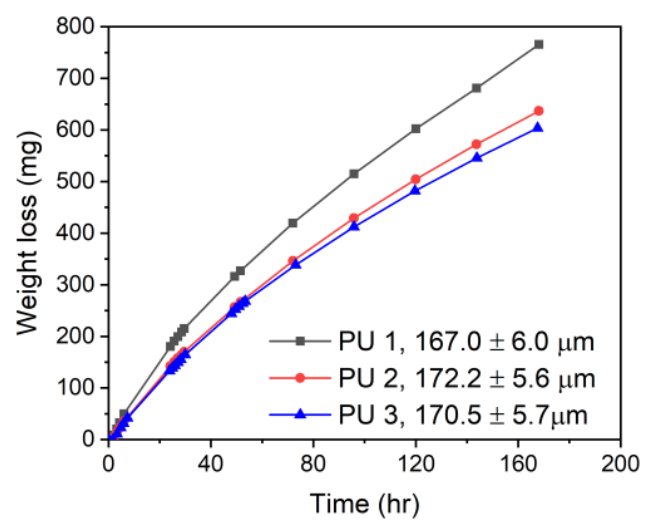

Fig. 8: Methanol weight loss from permeation cells with films of (a) NE-CA, (b) NE-PA, and (c) PU. A magnified view (red dashed rectangle) of the first 30 hours of the NE-CA films is shown in a subfigure of (a). The coating thicknesses are provided next to the sample names. 
For the NE-CA films, the cells begin to lose weight after approximately five hours (see the subfigure in Fig. 8(a)), suggesting the arrival of methanol at the outer surface of the films. This time lag is the so-called breakthrough time required by methanol to penetrate fully the NE-CA film. After the breakthrough time, a sharp and almost linear increase in weight loss is observed, suggesting a constant permeation rate of methanol. However, after ten hours, the permeation rate gradually declines. For NE-PA and PU films, methanol exhibits a similar phenomenon of a decreasing permeability as shown in Fig. 8(b) and (c). This declining permeation rate can be explained by a combination of the two factors discussed earlier: the leaching of solvents and plasticizers, and the physical crosslinking by Type II bound methanol. The leaching process contributes to a denser film with increases in the glass transition temperature, thereby decreasing the permeation rate. ${ }^{2,4}$ Type II bound methanol increases the effective crosslinking density and reduces the free volume, which again lowers the permeation rate.

The forming of Type I bound methanol is a fast process that can almost keep up with the moving diffusion front. ${ }^{25,27}$ Oppositely, the forming of type II bound methanol is a relatively slow process. This process is time and temperature dependent and requires longer time and higher temperatures for it to lead to an abundance of Type II bound methanol. Therefore, gradually, the permeability rate of methanol becomes lower as the continuous forming of Type II bound methanol increases. The rates of penetration and permeation of methanol across NE-CA, NE-PA, and PU films are provided in Table 4.

Table 4: Breakthrough velocity $\left(\mathrm{R}_{\mathrm{b}}\right)$ and permeation rate $\left(\mathrm{R}_{\text {perm }}\right)$ of methanol across NE-CA, NEPA, and PU films.

\begin{tabular}{|c|c|c|c|c|}
\hline \multirow{2}{*}{ Coating } & \multirow{2}{*}{$\begin{array}{c}\mathrm{R}_{\mathrm{b}^{\mathrm{a}}} \\
\left(\times 10^{-8} \mathrm{~m} / \mathrm{s}\right)\end{array}$} & \multicolumn{2}{|c|}{$\mathrm{R}_{\text {perm }}\left(\times 10^{-6} \mathrm{~mol} /\left(\mathrm{m}^{2} \cdot \mathrm{s}\right)\right)$} & \multirow{2}{*}{$\begin{array}{c}\text { Reduction of } \\
\mathrm{R}_{\text {perm }}{ }^{\mathrm{d}}(\%)\end{array}$} \\
\hline & & After breakthrough ${ }^{\mathrm{b}}$ & End $^{c}$ & \\
\hline NE-CA & 1.96 & 7.94 & 1.98 & 75.1 \\
\hline NE-PA & 0.48 & 3.10 & 1.23 & 60.3 \\
\hline PU & 2.25 & 9.48 & 4.07 & 57.1 \\
\hline
\end{tabular}

a. $R_{b}$ is the ratio of coating thickness to the breakthrough time $\left(=\delta_{\text {coating }} / t_{b}\right)$.

b. Average permeation rate in the first 24 hours after the breakthrough of methanol.

c. Average permeation rate from 144 to 168 hours.

d. Reduction of permeation rate $\left(=100-R_{\text {perm,end }} / R_{\text {perm,after breakthrough }} \times 100\right)$. 
In descending order of performance, the coating barrier properties are as follows: NE-PA > NE$\mathrm{CA}>\mathrm{PU}$. It can be seen that the rates of penetration and permeation all fall with increasing crosslinking density (see XLD in Table 2) and glass transition temperature (Table 3). Moreover, a significant reduction of the permeation rate $(\geq 50 \%)$ was observed for all three coatings.

\section{Permeability measurement across thermoplastic films}

To compare with the thermoset coatings, the permeability rate of methanol through two thermoplastic films, i.e., LDPE and PMMA films, were measured. The results are presented in Fig. 9.

(a)

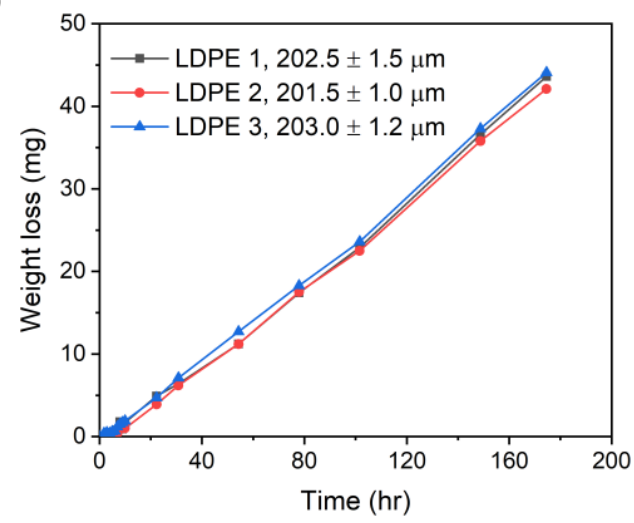

(b)

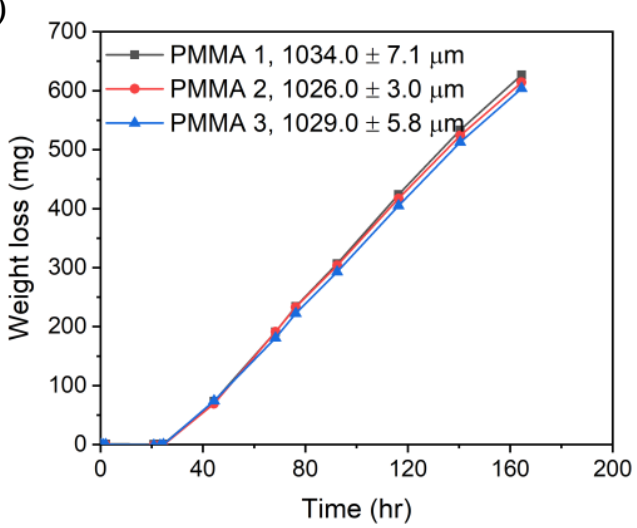

Fig. 9: Methanol weight loss from the permeation cell with films of (a) LDPE and (b) PMMA.

It can be seen that the rates of methanol permeation (i.e., the slopes) are approximately constant for LDPE and PMMA films after the breakthrough. Due to a lack of strong electronegative atoms (i.e., O, N and F), methanol cannot form hydrogen bonding with the LDPE matrix. Therefore, the LDPE films have a time-independent resistance to methanol. For the PMMA films, methanol can interact with ester groups via hydrogen bonding. However, without $\mathrm{NH}$ or $\mathrm{OH}$ groups in the PMMA matrix, only Type I bound methanol is possible, which explains the constant permeation rates of PMMA films. A constant permeation rate is expected when methanol is not bound or only forms one hydrogen bonding to the polymer network.

\section{Permeability measurement across methanol-exposed coating}

From the methanol absorption and desorption data, it was seen that the physical degradation of the three coatings came to a halt after immersion for approximately 168 hours. Therefore, a constant permeability rate is expected when using methanol-exposed coating films. Consequently, NE-CA 
films were pre-exposed to methanol [(NE-CA(Me)], that is, methanol absorption for 168 hours and then desorption for 168 hours prior to performing of permeability measurements. The results are shown in Fig. 10.

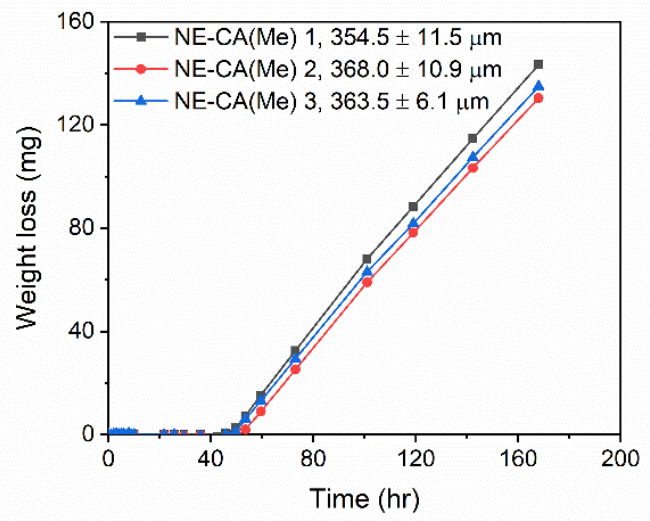

Fig. 10: Methanol weight loss from permeation cells of methanol-exposed NE-CA films (NE$\mathrm{CA}(\mathrm{Me})$ ) with 168 hours immersion in methanol. Prior to the permeation experiments, the NE-CA films were allowed unrestricted evaporation for 168 hours at room temperature.

It can be seen that the breakthrough time is about 50 hours, nine times higher than the original NECA samples, which significantly impedes the penetration process and prolongs the lifetime of the coating. After methanol breakthrough, an almost linear weight loss is seen, suggesting consistent coating properties. Physical degradation, i.e., leaching of a non-immobilized substance and forming of Type II bound methanol, almost completes after 168 hours immersion in methanol. In addition, this physical degradation is an irreversible process, that is, $\mathrm{NE}-\mathrm{CA}(\mathrm{Me})$ films do not revert to the original state after methanol desorption at room temperature. The average permeation rate is $1.63 \times 10^{-6} \mathrm{~mol} /\left(\mathrm{m}^{2} \cdot \mathrm{s}\right)$, which is $82 \%$ of the original samples after 168 hours (Table 4). A faster degradation takes place in the double-sided pre-exposed samples. The permeation rates of NE-CA samples in Fig. 8(a) tend to continuously decrease until eventually converges to the rate of the NE-CA(Me) samples.

\subsection{Water and ethanol absorption and desorption}

The mechanical and barrier properties of coatings were seen to improve after methanol exposure. Other hydroxyl solvents, i.e., water and ethanol, are expected to have similar effects and this was therefore investigated for NE-CA films and compared to the methanol experiments. The NE-CA 
films were immersed in the solvent at room temperature for 168 hours and then allowed to evaporate at room temperature for 168 hours. The associated weight changes are shown in Table 5 .

Table 5: Weight changes of NE-CA films after immersion for 168 hours $\left(M_{i}\right)$ followed by unrestricted evaporation for 168 hours $\left(\mathrm{M}_{1}\right)$.

\begin{tabular}{cccc}
\hline Solvent & $\mathrm{M}_{\mathrm{i}}(\mathrm{wt} \%)$ & $\mathrm{M}_{\mathrm{l}}(\mathrm{wt} \%)$ & $\mathrm{M}_{\mathrm{s}}(\mathrm{wt} \%)^{\mathrm{a}}$ \\
\hline Water & 2.24 & -0.56 & 2.80 \\
Ethanol & 5.60 & -2.56 & 8.15
\end{tabular}

a. $\mathrm{M}_{\mathrm{s}}=\mathrm{M}_{\mathrm{i}}-\mathrm{M}_{\mathrm{l}}$, is the approximate weight gain of solvent after immersion for 168 hours.

With a higher affinity to the novolac epoxy, methanol (Table 2) and ethanol cause much greater swelling than water upon absorption. In descending order of the amount leaching, the effects of solvents on the physical coating degradation are as follows: methanol > ethanol > water. The small molecular size and high affinity to the coating network contribute to the absorption of methanol, thereby resulting in the most severe physical degradation. DMA tests were performed on NE-CA films after solvent desorption and the results shown in Fig. 11.

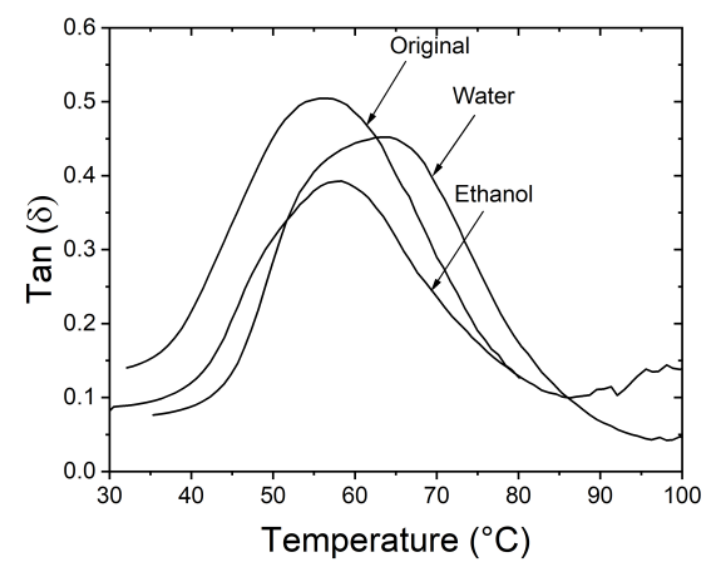

Fig. 11: Loss factors $[\tan (\delta)]$ of NE-CA films with 168 hours immersion in water and ethanol. All films were allowed unrestricted evaporation for 168 hours at room temperature prior to the DMA measurements.

For the films following water exposure, a slightly overlapping peak of the loss factor was observed, suggesting the forming of Type II bound water that forms multiple hydrogen bonds with the coating network, but the amount of bound water is small. The slow rate of water absorption 
decreases the rate of formation of Type II bound water. Therefore, a high temperature is often required to accelerate the water absorption and forming of Type II bound water. ${ }^{6,7}$ After ethanol exposure, a single peak of the loss factor was observed. This implies that ethanol does not form multiple hydrogen bonds to the coating network. The amount of absorbed ethanol is large (comparable to methanol), indicating the absorption process is not a determining factor for the forming of Type II bound ethanol. The molecular size of ethanol is greater than for water and methanol, which may not allow it to reach the sites for multiple hydrogen bonds. Moreover, the ethyl group of ethanol provides a steric hindrance effect and prevents the forming of multiple hydrogen bonds to the coating network. In comparison to water and ethanol, methanol is more efficient in evoking the physical degradation that improves the mechanical coating properties.

\section{Conclusions}

The mechanical and barrier properties of novolac epoxy and polyurethane coatings were significantly enhanced after physical degradation by methanol. Upon film penetration, methanol interacts with the coating network via hydrogen bonding. Two types of bound methanol exist: Type I bound methanol forms a single hydrogen bond with the coating network, whereas Type II bound methanol forms two hydrogen bonds. Type I bound methanol swells and plasticizes the coating network, accelerating the leaching of non-immobilized substances, such as plasticizers and residual solvents. In contrast, Type II bound methanol forms physical crosslinking and restricts the segmental mobility, thereby causing significant increases in the coating glass transition temperature and the associated declining rates of permeability. For two thermoplastic reference materials, the Type II bound methanol was not observed.

In comparison to water and ethanol, methanol causes more severe physical degradation, i.e., higher degrees of leaching and a faster rate of formation of the Type II bound complex. The enhancement

of the mechanical and the barrier properties of the films suggests that, potentially, methanol exposure can be applied to improve coatings performance.

\section{Acknowledgements}

Financial support from the Hempel Foundation to CoaST (The Hempel Foundation Coatings Science and Technology Centre) is gratefully acknowledged. 


\section{References}

1 (Journal Article) Sørensen, PA, Kiil, S, Dam-Johansen, K, Weinell, CE, "Anticorrosive coatings: A review." J Coatings Technol Res, 6 (2) 135-176 (2009).

2 (Journal Article) Møller, VB, Dam-Johansen, K, Frankær, SM, Kiil, S, "Acid-resistant organic coatings for the chemical industry: a review." J Coatings Technol Res, 14 (2) 279-306 (2017).

3 (Journal Article) VanLandingham, MR, Eduljee, RF, Gillespie, JW, "Moisture Diffusion in Epoxy Systems." J Appl Polym Sci, 71 (5) 787-798 (1999).

4 (Journal Article) Marais, S, Metayer, M, Nguyen, TQ, Labbe, M, Saiter, JM, "Diffusion and permeation of water through unsaturated polyester resins - influence of resin curing." Eur Polym J, 36 (3) 453-462 (2000).

5 (Journal Article) Nogueira, P, Ramírez, C, Torres, A, Abad, MJ, Cano, J, López, J, et al., "Effect of water sorption on the structure and mechanical properties of an epoxy resin system." J Appl Polym Sci, 80 (1) 71-80 (2001).

6 (Journal Article) Han, SO, Drzal, LT, "Water absorption effects on hydrophilic polymer matrix of carboxyl functionalized glucose resin and epoxy resin." Eur Polym J, 39 (9) 1791-1799 (2003).

7 (Journal Article) Zhou, J, Lucas, JP, "Hygrothermal effects of epoxy resin. Part I: the nature of water in epoxy." Polymer (Guildf), 40 (20) 5505-5512 (1999).

8 (Journal Article) Zhou, J, Lucas, JP, "Hygrothermal effects of epoxy resin. Part II: variations of glass transition temperature." Polymer (Guildf), 40 (20) 5513-5522 (1999).

9 (Journal Article) Barral, L, Cano, J, López, J, Nogueira, P, Ramírez, C, Abad, MJ, "Water Sorption in Tetrafunctional Phenol Novolac Epoxy Mixtures Cured with a Diamine." J Therm Anal Calorim, 52 (3) 823-830 (1998).

10 (Journal Article) Abeysinghe, HP, Edwards, W, Pritchard, G, Swampillai, GJ, "Degradation of crosslinked resins in water and electrolyte solutions." Polymer (Guildf), 23 (12) 1785-1790 (1982).

11 (Journal Article) El-Tantawy, F, "Influence of solvent transport on physico-chemical properties of crosslinked butyl rubber filled with TiC ceramic." Polym Degrad Stab, 73 (2) 289-299 (2001).

12 (Journal Article) Sonawala, SP, Spontak, RJ, "Degradation kinetics of glass-reinforced 
polyesters in chemical environments: Part II. Organic solvents." J Mater Sci, 31 (18) 4757-4765 (1996).

13 (Journal Article) Tsuda, K, "Behavior and mechanisms of degradation of thermosetting plastics in liquid environments." J Japan Pet Inst, 50 (5) 240-248 (2007).

14 (Journal Article) Kaplan, ML, "Solvent penetration in cured epoxy networks." Polym Eng Sci, 31 (10) 689-698 (1991).

15 (Chapter in an Edited Book) Dalena, F, Senatore, A, Marino, A, Gordano, A, Basile, M, Basile, A, "Methanol Production and Applications: An Overview." In: Basile A, Dalena F, editors. Methanol: Science and Engineering. Elsevier B.V., 2018: 3-28.

16 (Website) Methanol Institute, "Atmospheric above ground tank storage of methanol." (2018). http://www.methanol.org/wpcontent/uploads/2016/06/AtmosphericAboveGroundTankStorageMethanol-1.pdf (accessed 10 Jun 2020).

17 (Journal Article) Vesely, D, "Molecular sorption mechanism of solvent diffusion in polymers." Polymer (Guildf), 42 (9) 4417-4422 (2001).

18 (Journal Article) Kotnarowska, D, "Influence of ultraviolet radiation and aggressive media on epoxy coating degradation." Prog Org Coatings, 37 (3) 149-159 (1999).

19 (Journal Article) Dang, W, Kubouchi, M, Yamamoto, S, Sembokuya, H, Tsuda, K, "An approach to chemical recycling of epoxy resin cured with amine using nitric acid." Polymer (Guildf), 43 (10) 2953-2958 (2002).

20 (Journal Article) Feng, J, Berger, KR, Douglas, EP, "Water vapor transport in liquid crystalline and non-liquid crystalline epoxies." J Mater Sci, 39 (10) 3413-3423 (2004).

21 (Journal Article) Mitra, S, Ahire, A, Mallik, BP, "Investigation of accelerated aging behaviour of high performance industrial coatings by dynamic mechanical analysis." Prog Org Coatings, 77 (11) 1816-1825 (2014).

22 (Journal Article) Gao, T, He, Z, Hihara, LH, Mehr, HS, Soucek, MD, "Outdoor exposure and accelerated weathering of polyurethane/polysiloxane hybrid coatings." Prog Org Coatings, 130 (December 2018) 44-57 (2019).

23 (Journal Article) Møller, VB, Wang, T, Dam-Johansen, K, Frankær, SM, Kiil, S, "Diffusion cell investigations into the acidic degradation of organic coatings." J Coatings Technol Res, 15 (6) (2018). doi:10.1007/s11998-018-0094-z. 
24 (Journal Article) Sørensen, PA, Dam-Johansen, K, Weinell, CE, Kiil, S, "Cathodic delamination: Quantification of ionic transport rates along coating-steel interfaces." Prog Org Coatings, 67 (2) 107-115 (2010).

25 (Journal Article) Zhu, M, Vesely, D, "The effect of polymer swelling and resistance to flow on solvent diffusion and permeability." Eur Polym J, 43 (10) 4503-4515 (2007).

26 (Journal Article) Guo, CJ, De Kee, D, Harrison, B, "Diffusion of organic solvents in rubber membranes measured via a new permeation cell." J Appl Polym Sci, 56 (7) 823829 (1995).

27 (Journal Article) Vesely, D, "Diffusion of liquids in polymers." Int Mater Rev, 53 (5) 299-315 (2008).

28 (Journal Article) Wang, T, José, J, Graversen, E, Erik, C, Dam-Johansen, K, "Simultaneous tracking of hardness, reactant conversion, solids concentration, and glass transition temperature in thermoset polyurethane coatings (accepted)." J Coatings Technol Res (2020).

29 (Chapter in an Edited Book) David, V, Grinberg, N, Moldoveanu, SC, "Long-Range Molecular Interactions Involved in the Retention Mechanisms of Liquid Chromatography." In: Grushka E, Grinberg N, editors. Advances in Chromatography. CRC Press, 2017 doi:10.1201/9781315116372. 